\title{
Crude oil yield and properties of rice bran oil from different varieties as affected by extraction conditions using soxhterm method
}

\begin{abstract}
The current study was employed to investigate the effect of solvent type, extraction time and bran ratio on the rice bran oil (RBO) properties from three varieties of rice bran namely Bario, lowland and upland rice. RBO was extracted by using soxtherm extraction method using methanol solvent at different extraction time (3, 4 and $5 \mathrm{~h})$ and bran ratio $(10,20$ and $30 \mathrm{~g}$ ). Free fatty acid (FFA), total phenolic content (TPC) and antioxidant properties were assessed. Solvent that has low polarity exhibited the attraction of polar component of oil with the highest yield by ethanol (16.16\%), followed by methanol (15.38\%). FFA contents occurred higher in lowland types of rice bran in all types of solvents at $\mathrm{P}<0.05$ with ethanol (12.73\%), methanol (11.96\%) and hexane (11.13\%), while the total phenolic content and antioxidant properties were influenced by the types of rice bran and solvents used for extracting components out of the bran. The highest phenolic content in the crude oil was extracted using ethanol in lowland $(0.509 \mathrm{mg} / \mathrm{ml})$, and the lowest was extracted by hexane in Bario $(0.061 \mathrm{mg} / \mathrm{ml})$. The highest antioxidant activity was observed in RBO extracted using methanol of lowland (73.74\%) and RBO extracted using ethanol of upland (73.65\%), while the lowest were observed in RBO extracted using hexane. The different types of solvent have the significant impact on the crude oil yield and properties of crude oil extracted.
\end{abstract}

Keyword: Antioxidant; Free fatty acid; Rice bran oil; Solvent extraction; Soxtherm; Total phenolic content 